\title{
Sleep-disordered breathing and asthma: evidence from a large multicentric epidemiological study in China
}

\author{
Liwen Li ${ }^{1,2}$, Zhiwei Xu ${ }^{3}$, Xingming Jin ${ }^{4}$, Chonghuai Yan ${ }^{1}$, Fan Jiang ${ }^{4}$, Shilu Tong ${ }^{3}$, Xiaoming Shen ${ }^{5^{*}}$ \\ and Shenghui $\mathrm{Li}^{2,5^{*}}$
}

\begin{abstract}
Background: Previous studies have postulated that sleep-disordered breathing (SDB) may be associated with the occurrence and exacerbation of asthma. However, there was limited quantitative evidence on the topic. This study aimed at investigating the prevalence and predisposing factors of asthma, and quantifying the association between SDB and asthma among school-aged children in China. In addition, a comprehensive meta-analysis of the published evidences and our findings were further conducted.

Methods: To test the hypothesis, we conducted a multicentric cross-sectional study involving 22,478 children aged 5-12 years recruited from eight cities in China. Furthermore, a meta-analysis based on both previously published studies and our cross-sectional study was performed.

Results: The prevalence rate of SDB and asthma was $12.0 \%$ and $3.5 \%$ among our cross-sectional study sample. It was demonstrated that symptoms of SDB, such as habitual snoring ( $\mathrm{OR}=1.28,95 \% \mathrm{Cl}: 1.01-1.62)$, and obstructive sleep apnea (OSA) (OR = 1.92, 95\% Cl: 1.34-2.76), were significantly associated with asthma, after adjusting for potential confounding factors. In the meta-analysis, SDB was correlated with the prevalence of asthma in both children $(\mathrm{OR}=1.58,95 \% \mathrm{Cl}: 1.35-1.80)$ and adults $(\mathrm{OR}=1.55,95 \% \mathrm{Cl}: 1.42-1.67)$.

Conclusions: Our results provide further evidence for the independent association between SDB and asthma. The clinical significance of our findings lies in the emphasis that children undergoing examination or treatment for asthma should be routinely screened for sleep problems. Further systematic study is required to illuminate the underlying mechanism.
\end{abstract}

Keywords: Children, Asthma, Sleep-disordered breathing, Cross-sectional, Meta-analysis

\section{Introduction}

Asthma is one of the primary causes of chronic respiratory disorders [1]. Over the last quarter century, a dramatic increase in the morbidity and economic burden of asthma has become a public concern [2]. It was reported that at least $5 \%$ of the general population suffered from asthma $[3,4]$. Obesity is a well-established risk factor for asthma in adults, but the mechanism underlying the

\footnotetext{
* Correspondence: shenxm9907@126.com; Lsh9907@163.com

${ }^{5} \mathrm{MOE}$ - Shanghai Key Laboratory of Children's Environmental Health, Xinhua Hospital, Shanghai Jiao Tong University School of Medicine, 1665 Kong Jiang Road, Shanghai 200092, China

${ }^{2}$ School of Public Health, Shanghai Jiao Tong University School of Medicine, 227 South Chongqing Road, Shanghai 200127, PR China

Full list of author information is available at the end of the article
}

association is still far from clear [5]. Epidemiological studies suggested that obesity and obesity related comorbidities, including sleep-disordered breathing (SDB) and gastro-oesophageal reflux (GOR), were highly prevalent in children with asthma [6-8].

SDB and asthma share similar diurnal and nocturnal symptoms. Airway obstruction is involved in the pathogenesis of both diseases $[9,10]$. The term "SDB" refers to a spectrum of abnormal breathing and/or gas exchange patterns during sleep. It is characterized by habitual loud snoring and increased respiratory effort. Habitual snoring, upper airway resistance syndrome (UARS), obesity hypoventilation, obstructive sleep apnea (OSA), and central sleep apnea are the primary syndromes that fall 
under the rubric of SDB [11]. The first report regarding the significant association between habitual snoring and history of exercise-induced asthma can date back to 1992 [12]. Since then, several studies have been conducted to explore the correlation between sleep disturbance and asthma in SDB patients. [13-17]. However, few studies investigated the prevalence of SDB in asthma patients. To our knowledge, so far, only three, two crosssectional and one cohort, studies examined the prevalence of SDB in children with a confirmed diagnosis of asthma [18-20]. Epidemiological data also demonstrated that sleep disturbance is more prevalent in school-aged children with atopic disease, such as hay fever and atopic dermatitis $[21,22]$. Based on the existing body of knowledge, we hypothesized that SDB may be associated with both the occurrence of asthma and asthma severity. The present study aimed at: I) estimating the prevalence rate of asthma; II) evaluating whether SDB was an independent risk factor for asthma among school-aged children in China; and III) further quantifying the relationship between SDB and prevalence and severity of asthma by conducting a meta-analysis quantitatively incorporating the results from recently published studies.

\section{Materials and methods}

\section{Multicentric cross-sectional study}

\section{Study design and subjects}

The study design and subjects recruitment protocol have been described in previous studies $[15,23,24]$. The large national cross-sectional survey was performed in eight Chinese cities in November and December, 2005. A total of 22,478 school-aged children were recruited from six grades of 55 eligible primary schools in 39 districts of eight cities. Out of 22,478 children, 20,672 (91.9\%), with a mean age of 9.00 years old $(\mathrm{SD}=1.61$; ranged from 5.08 to 12.00 years old), returned completed questionnaires.

The protocol of our study was approved by the Ministry of Education of People's Republic of China and Ethics Committee of Shanghai Jiaotong University, School of Medicine.

\section{Measures}

\section{Asthma}

Asthma was assessed by addressing the following question to their guardians, "Did pediatricians or pediatric health professionals ever make a diagnosis of asthma for your child?" Answers were coded using a 2-point scale: "0" for no and " 1 " for yes.

\section{SDB}

The sleep behaviors of subjects were evaluated by Children's Sleep Habits Questionnaire (CSHQ), which was designed to assess sleep characteristics of pre-school and schoolaged children ( 4 to 12 years old) [23,25]. The sensitivity and reliability of CSHQ have been described in previous studies [15,24].

Three items are included in the subscale regarding the SDB-related signs and symptoms in the CSHQ. The testretest reliability (ICCs) and the internal consistency (Cronbach's alpha) of the SDB subscale are 0.76 and 0.42 , respectively. The first question is "How often does your child snore loudly during a typical recent week?". The second question is "How often does your child have snorts and gasps during sleep on a typical recent week?". And the third one is "How often does your child have stopped or interrupted breathing during sleep on a typical recent week?".

According to the CSHQ, the question is rated on a 3point scale: "almost always" for 5 to 7 nights per week; "frequently" for 2 to 4 nights per week; and "occasionally/ never" for 0 to 1 night per week. For this study, a SDBaffected subject was defined as an individual SDB problem occurring at least two nights per week.

\section{Associated factors of asthma}

The potential risk factors were conceptually divided into four categories: (1) socioeconomic variables, i.e. family structure, parents' educational levels and household income; (2) demographic variables, i.e. children's gender, age and ethnicity; (3) general chronic health problem variables, i.e. overweight/obesity status, history of food/drug allergy and gastro-oesophageal reflux; and (4) respiratory condition, i.e. history of chronic allergic rhinitis diagnosis, frequency of upper respiratory infection and history of hypertrophy of tonsils diagnosis.

\section{Data analysis}

Statistical descriptions including mean, percentage of categorical variables and standard deviation of continuous variables were calculated. Logistic regression was used to assess the association between asthma and symptoms of SDB (Table 1 and 2). All statistical analyses were performed by SPSS version 13.5 (SPSS Inc, Chicago, IL, USA). Two-sided $P$ value less than 0.05 was considered as statistical significant.

\section{Meta-analysis}

Literature search

We also conducted a meta-analysis of all published crosssectional and cohort studies on the correlation between SDB and asthma. Relevant studies published up to June 15, 2014 were retrieved in the MEDLINE, EMBASE, and Chinese National Knowledge Infrastructure (CNKI), without any language restriction, using the following terms: ('asthma' or 'bronchial asthma') and ('sleep disorders' or 'sleep apnea syndromes' or 'sleep-disordered breathing' or 'SDB' or 'snoring' or 'habitual snoring' or 'sleep apnea, obstructive' or 'OSA') and ('child' or 'infant' or 'child, preschool' or 'adolescent' or 'adolescent' or 'middle aged' or 
Table 1 Associated factors regarding asthma by univariate logistical regression models

\begin{tabular}{|c|c|c|c|}
\hline \multirow[t]{2}{*}{ Variables (n, \%) } & \multirow[t]{2}{*}{ Prevalence of asthma $n$ ( $n$ \%) } & \multicolumn{2}{|c|}{ Univariate regression models } \\
\hline & & OR $(95 \% \mathrm{Cl})$ & $P$ value \\
\hline \multicolumn{4}{|c|}{ Demographic and socioeconomic characteristics } \\
\hline \multicolumn{4}{|l|}{ Age (years) } \\
\hline $5-6(2543,12.3 \%)$ & $101(4.0)$ & $1.86(1.36-2.56)$ & $<.001$ \\
\hline 7- $(3802,18.4 \%)$ & $141(3.7)$ & $1.73(1.28-2.34$ & $<.001$ \\
\hline 8- $(3839,18.6 \%)$ & $128(3.3)$ & $1.55(1.15-2.10)$ & 0.005 \\
\hline 9- $(3798,18.4 \%)$ & $131(3.4)$ & $1.61(1.19-2.18)$ & 0.002 \\
\hline $10-(3724,18.0 \%)$ & $134(3.6)$ & $1.68(1.24-2.27)$ & 0.001 \\
\hline $11-(2943,14.3 \%)$ & $64(2.2)$ & Ref. & \\
\hline \multicolumn{4}{|l|}{ Gender (\%) } \\
\hline Boys (10227, 49.5\%) & $434(4.2)$ & $1.67(1.44-1.96)$ & $<.001$ \\
\hline Girls $(10445,50.5 \%)$ & $269(2.6)$ & Ref. & \\
\hline \multicolumn{4}{|l|}{ Ethnicity } \\
\hline Han ethnic group (19604, 94.9\%) & $674(3.4)$ & $1.40(0.94-2.08)$ & 0.097 \\
\hline Minority ethnic group (1030, 5.1\%) & $26(2.5)$ & Ref. & \\
\hline \multicolumn{4}{|l|}{ Family income } \\
\hline$<800(3956,19.3 \%)$ & $67(1.7)$ & Ref. & \\
\hline $800-2500(11612,56.6 \%)$ & $344(3.0)$ & $1.77(1.36-2.31)$ & $<.001$ \\
\hline$\geq 2500(4966,24.2 \%)$ & $284(5.7)$ & $3.52(2.69-4.61)$ & $<.001$ \\
\hline Family structure & & & 0.067 \\
\hline Single parent family $(1103,5.3 \%)$ & $41(3.7)$ & $1.17(0.85-1.63)$ & 0.328 \\
\hline Large family $(6565,31.7 \%)$ & $249(3.8)$ & $1.20(1.02-1.41)$ & 0.024 \\
\hline Nuclear family $(13014,62.9 \%)$ & $413(3.2)$ & Ref. & \\
\hline Mather's education level & & & $<.001$ \\
\hline Low $(5752,28.2 \%)$ & $118(2.1)$ & Ref. & \\
\hline Medium $(6825,33.4 \%)$ & $204(3.0)$ & $1.47(1.17-1.85)$ & 0.001 \\
\hline High $(7843,38.4 \%)$ & $370(4.7)$ & $2.37(1.92-2.92)$ & $<.001$ \\
\hline Father's education level & & & $<.001$ \\
\hline Low $(4940,23.9 \%)$ & $109(2.2)$ & Ref. & \\
\hline Medium $(7075,34.2 \%)$ & $215(3.0)$ & $1.39(1.10-1.76)$ & 0.006 \\
\hline High $(8647,41.8 \%)$ & $379(4.4)$ & $2.03(1.64-2.52)$ & $<.001$ \\
\hline \multicolumn{4}{|l|}{ General chronic health problems } \\
\hline \multicolumn{4}{|l|}{ Overweight/obesity } \\
\hline Obesity $(1323,8.2 \%)$ & $58(4.4)$ & $1.44(1.08-1.91)$ & 0.012 \\
\hline Overweight $(2206,13.6 \%)$ & $91(4.1)$ & $1.35(1.07-1.71)$ & 0.011 \\
\hline Normal (12656, 78.2\%) & $391(3.1)$ & Ref. & \\
\hline \multicolumn{4}{|l|}{ Food/drug allergy } \\
\hline Yes $(1176,5.7 \%)$ & $139(11.8)$ & $4.53(3.72-5.51)$ & $<.001$ \\
\hline No $(19588,94.3 \%)$ & $565(2.9)$ & Ref. & \\
\hline \multicolumn{4}{|l|}{ Gastro-oesophageal reflux } \\
\hline Yes $(159,0.8 \%)$ & 19 (11.9) & $3.97(2.44-6.45)$ & $<.001$ \\
\hline No $(20609,99.2 \%)$ & $686(3.3)$ & Ref. & \\
\hline
\end{tabular}

Respiratory diseases 
Table 1 Associated factors regarding asthma by univariate logistical regression models (Continued)

\begin{tabular}{|c|c|c|c|}
\hline \multicolumn{4}{|c|}{ History of chronic allergic rhinitis diagnosis } \\
\hline Yes $(1993,9.6 \%)$ & $310(15.6)$ & $8.65(7.39-10.12)$ & $<.001$ \\
\hline No $(18764,90.4 \%)$ & $392(2.1)$ & Ref. & \\
\hline \multicolumn{4}{|l|}{ Upper respiratory infection } \\
\hline Frequently (3607 17.4\%) & $350(9.7)$ & $5.09(4.37-5.93)$ & $<.001$ \\
\hline Occasionally $(17164,82.6 \%)$ & $355(2.1)$ & Ref. & \\
\hline \multicolumn{4}{|c|}{ History of hypertrophy of tonsils diagnosis } \\
\hline Yes $(2369,11.4 \%)$ & $123(5.2)$ & $1.68(1.38-2.05)$ & $<.001$ \\
\hline No $(18404,88.6 \%)$ & $582(3.2)$ & Ref. & \\
\hline \multicolumn{4}{|c|}{ Symptoms of sleep disordered breathing } \\
\hline \multicolumn{4}{|l|}{ Habitual snoring } \\
\hline Usually/Often $(2525,12.2 \%)$ & $160(6.3)$ & $2.20(1.83-2.64)$ & $<.001$ \\
\hline Occasionally/No $(18234,87.8 \%)$ & $544(3.0)$ & Ref. & \\
\hline \multicolumn{4}{|l|}{ Stops breathing } \\
\hline Usually/Often $(282,1.4 \%)$ & $24(8.5)$ & $2.71(1.77-4.15)$ & $<.001$ \\
\hline Occasionally/No (20419, 98.6\%) & $677(3.3)$ & Ref. & \\
\hline \multicolumn{4}{|l|}{ Snorts and gasps } \\
\hline Usually/Often (640, 3.1\%) & $80(12.5)$ & $4.47(3.49-5.72)$ & $<.001$ \\
\hline Occasionally/No (20071, 96.9\%) & $622(3.1)$ & Ref. & \\
\hline
\end{tabular}

OR, odds ratio; $\mathrm{Cl}$, confidence interval.

'young adult' or 'aged'). Bibliographies of retrieved articles were also reviewed to identify additional eligible articles.

\section{Data extraction}

For each study, we documented information on the first author's last name, year of publication, country of subject, ethnicities, study design, questionnaire response rate, follow-up period if available, total number of subjects recruited, mean age (or range), symptoms of SDB, and study-specific odd ratios (95\% CIs). Ethnicity was categorized as Caucasian, African, Asian, or mixed for studies including subjects of more than one ethnicity. In addition, basic information of each study including country, time and authorship were screened to exclude the duplicated publication.. All data from eligible studies were recorded independently by two authors with a piloted data standardized form and compared afterwards. In cases of conflicting evaluations, minor discrepancies were resolved by a third investigator's careful full-text reexamination.

\section{Statistical analysis}

Odd ratios (ORs) with corresponding 95\% CIs were applied to assess the strength of association of SDB and asthma. Heterogeneity was checked by a Cochran's Q-statistic, a

Table 2 Associations of SDB symptoms with asthma by multivariate logistical regression models

\begin{tabular}{|c|c|c|c|c|c|c|}
\hline \multirow[t]{2}{*}{ Variables } & \multicolumn{2}{|l|}{ Model I } & \multicolumn{2}{|l|}{ Model II } & \multicolumn{2}{|l|}{ Model III } \\
\hline & OR $(95 \% \mathrm{Cl})$ & $P$ & OR $(95 \% \mathrm{Cl})$ & $P$ & OR $(95 \% \mathrm{Cl})$ & $P$ \\
\hline \multicolumn{7}{|l|}{ Habitual snoring } \\
\hline Usually/Often & $1.97(1.63-2.38)$ & $<0.001$ & $1.74(1.39-2.16)$ & $<0.001$ & $1.28(1.01-1.62)$ & 0.041 \\
\hline Occasionally/No & Ref. & & Ref. & & Ref. & \\
\hline \multicolumn{7}{|l|}{ Snorts and gasps } \\
\hline Usually/Often & $4.45(3.41-5.82)$ & $<0.001$ & $3.17(2.26-4.23)$ & $<0.001$ & $1.92(1.34-2.76)$ & $<0.001$ \\
\hline Occasionally/No & Ref. & & Ref. & & Ref. & \\
\hline
\end{tabular}

OR, odds ratio; $\mathrm{Cl}$, confidence interval.

Model I only adjusted for demographic and socioeconomic characteristics (age, gender, ethnicity, family income, family structure, mother's education level, and father's education level).

Model II adjusted for demographic and socioeconomic characteristics and, further, general chronic health problems (overweight/obesity, food/drug allergy, and gastro-oesophageal reflux).

Model III adjusted for demographic and socioeconomic characteristics, general chronic health problem, and respiratory diseases (history of chronic allergic rhinitis diagnosis, upper respiratory infection, and history of hypertrophy of tonsils diagnosis) simultaneously. 
$P$-value less than 0.01 was considered as statistically significant [26]. The $I^{2}$ test was also used to quantify heterogeneity in terms of percentage (ranging from 0 to $100 \%$ ) [27]. $P<0.01$ for $Q$-test or $I^{2}>50 \%$ indicated the existence of heterogeneity between studies. Fixed-effect model (Mantel-Haenszel method) was used to pool the data in the existence of betweenstudy heterogeneity; otherwise, a random-effect model (DerSimonian-Laird method) should be applied. To evaluate the robustness of the results, a one-way sensitivity analysis was conducted to evaluate the impact of individual study on the pooled results by omitting each study in turn. Egger's linear regression test and Funnel plot were applied to assess whether the validity of the estimate might be affected by publication bias [28]. The statistical significance of the pooled data was assessed by $Z$ test. All the statistical analyses were conducted using STATA version 12.0 (Stata Corp, College Station, TX, USA).

\section{Results}

\section{Cross-sectional study}

Among all the recruited children, $3.4 \%$ of them suffered from lifetime asthma with confirmed diagnosis. The influence of potential contributing factors was also assessed. There was a significant gender difference in the prevalence of asthma (boys: $4.2 \%$ vs. girls: $2.6 \% ; P<0.001)$. In addition, the changing pattern of asthma prevalence in school children manifested a "V" shaped curve, dropping slightly from age 5 to 8 , then gradually rising from age 9 to 12 .

Table 1 presents the sample characteristics and their associations with asthma diagnosis by univariate analyses. It can be seen that significant differences exist in each demographic variable between asthmatics and non-asthmatics. In univariate regression models, it was revealed that current habitual snoring and OSA may be significant risk factors for asthma.

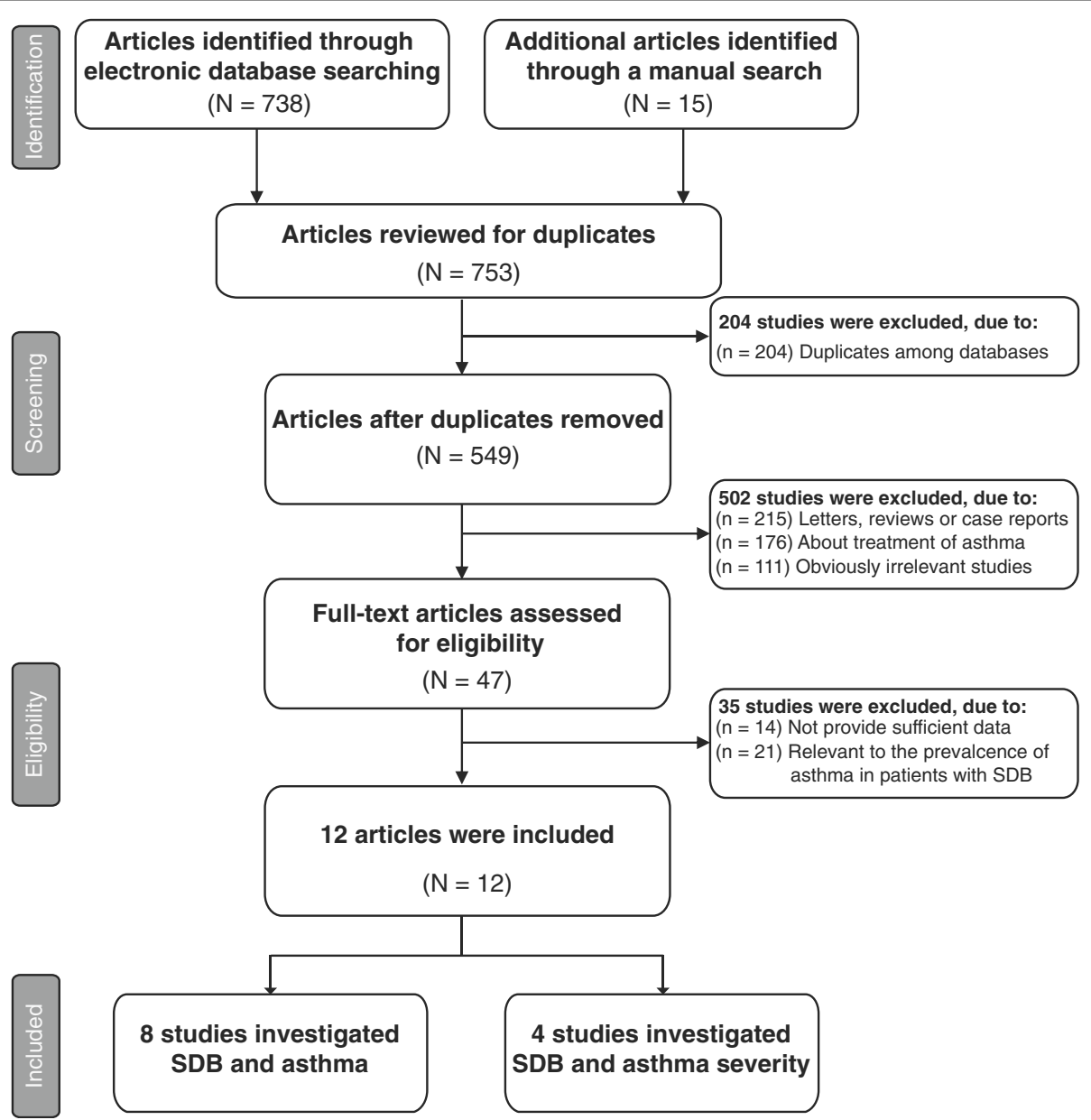

Figure 1 Flow diagram of the selection process of the included/excluded studies in the meta-analysis. 
Multivariate logistic regression was further used to model the association of habitual snoring and OSA with asthma, while adjusting for potential confounders. As shown in Table 2, an initial multivariate analysis was performed to adjust for demographic and socioeconomic variables. The results showed that habitual snoring and OSA are significantly associated with asthma, with odds ratios (ORs) ranging from 1.63 to 5.85. Two additional multivariate models were also conducted, characterized by additional adjustments for asthmarelated variables including general chronic health problema and respiratory diseases. Both habitual snoring $(\mathrm{OR}=1.28,95 \% \mathrm{CI}: 1.01-1.62)$ and $\mathrm{OSA}(\mathrm{OR}=1.92$,
95\%CI: $1.34-2.76)$ remain to be a statistically significant predictor of asthma.

\section{Meta-analysis}

The flow chart showed the process of study selection and exclusion/inclusion criteria in the meta-analysis (Figure 1). 12 studies (not including our cross-sectional study) with 38,766 subjects were included in the analyses [18-20,29-37]. Characteristics of the studies and subjects included were presented in Table 3 . Of the 12 included studies, nine were cross-sectional studies, two were cohort studies, and the other one was a case-control study. The sample sizes of included studies range from 60

Table 3 Summary of studies assessing the association of SDB and asthma and its severity risk

\begin{tabular}{|c|c|c|c|c|c|c|c|c|c|c|}
\hline $\begin{array}{l}\text { First author, } \\
\text { year }\end{array}$ & Country & Ethnicity & Study design & $\begin{array}{l}\text { Response } \\
\text { rate }\end{array}$ & Size & $\begin{array}{l}\text { Male } \\
(\%)\end{array}$ & Age (y) & $\begin{array}{l}\text { Risk } \\
\text { factor }\end{array}$ & Outcome & $\begin{array}{l}\text { OR } \\
{[95 \% \mathrm{Cl}]}\end{array}$ \\
\hline \multirow[t]{4}{*}{$\begin{array}{l}\text { Teodorescu, } \\
2012 \text { [37] }\end{array}$} & USA & African 6\% & Cross-sectional & $93 \%$ & 752 & $33 \%$ & $47 \pm 14$ & $\begin{array}{l}\text { High OSA } \\
\text { risk }\end{array}$ & $\begin{array}{l}\text { Persistent daytime } \\
\text { asthma }\end{array}$ & $\begin{array}{l}1.96[1.31 \\
2.94]\end{array}$ \\
\hline & & $\begin{array}{l}\text { Caucasians } \\
91 \%\end{array}$ & & & & & & & $\begin{array}{l}\text { Persistent } \\
\text { nighttime asthma }\end{array}$ & $\begin{array}{l}1.97[1.32, \\
2.94]\end{array}$ \\
\hline & & Others 3\% & & & & & & OSA & $\begin{array}{l}\text { Persistent daytime } \\
\text { asthma }\end{array}$ & $\begin{array}{l}2.08[1.13 \\
3.82]\end{array}$ \\
\hline & & & & & & & & & $\begin{array}{l}\text { Persistent } \\
\text { nighttime asthma }\end{array}$ & $\begin{array}{l}1.48[0.82, \\
2.69]\end{array}$ \\
\hline Ross, 2012 [36] & USA & $\begin{array}{l}\text { African/ } \\
\text { Caucasians }\end{array}$ & Cross-sectional & $54 \%$ & 108 & $67.60 \%$ & $9.1 \pm 3.4$ & SDB & Asthma severity & $\begin{array}{l}3.62[1.26 \\
5.40]\end{array}$ \\
\hline $\begin{array}{l}\text { Lukrafka, } \\
2010[20]\end{array}$ & Brazil & Caucasians & Cross-sectional & $93.50 \%$ & 575 & $49.80 \%$ & $\begin{array}{l}\text { Range } \\
12-19\end{array}$ & Snoring & Asthma & $\begin{array}{l}4.50[3.30, \\
6.20]\end{array}$ \\
\hline $\begin{array}{l}\text { Teodorescu, } \\
2009 \text { [35] }\end{array}$ & USA & Caucasians & Cross-sectional & $93 \%$ & 244 & $39 \%$ & $46 \pm 13$ & $\begin{array}{l}\text { Habitual } \\
\text { snoring }\end{array}$ & Asthma & $\begin{array}{l}2.16[1.13 \\
4.10]\end{array}$ \\
\hline \multirow[t]{4}{*}{$\begin{array}{l}\text { Kozyrskyj, } \\
2009[19]\end{array}$} & Australia & Caucasians & Cohort study & $83.40 \%$ & 1,999 & NA & $\begin{array}{l}\text { Range } \\
11-14\end{array}$ & $\begin{array}{l}\text { Habitual } \\
\text { snoring }\end{array}$ & $\begin{array}{l}\text { Persistent asthma } \\
\text { (6 yrs) }\end{array}$ & $\begin{array}{l}1.51[1.04 \\
2.20]\end{array}$ \\
\hline & & & & & 1,365 & & & & $\begin{array}{l}\text { Non-atopic } \\
\text { asthma (6 yrs) }\end{array}$ & $\begin{array}{l}2.78[1.51, \\
5.09]\end{array}$ \\
\hline & & & & & 1,693 & & & & $\begin{array}{l}\text { Persistent asthma } \\
\text { (14 yrs) }\end{array}$ & $\begin{array}{l}1.74[1.05 \\
2.90]\end{array}$ \\
\hline & & & & & 1,390 & & & & $\begin{array}{l}\text { Non-atopic } \\
\text { asthma (14 yrs) }\end{array}$ & $\begin{array}{l}2.29[1.11 \\
4.71]\end{array}$ \\
\hline \multirow[t]{2}{*}{$\begin{array}{l}\text { Jamrozik, } \\
2009[34]\end{array}$} & Australia & Caucasians & Cohort study & $47.30 \%$ & 1,554 & $44.5 \%$ & $\begin{array}{l}\text { Range } \\
20-69\end{array}$ & Snore & $\begin{array}{l}\text { Newly diagnosed } \\
\text { asthma }\end{array}$ & $\begin{array}{l}1.20[0.90 \\
1.70]\end{array}$ \\
\hline & & & & & & & & $\begin{array}{l}\text { Habitual } \\
\text { snoring }\end{array}$ & $\begin{array}{l}\text { Newly diagnosed } \\
\text { asthma }\end{array}$ & $\begin{array}{l}2.40[1.40, \\
4.20]\end{array}$ \\
\hline $\begin{array}{l}\text { Karachaliou, } \\
2007 \text { [33] }\end{array}$ & Greece & Caucasians & Cross-sectional & NA & 1,501 & $59.40 \%$ & $\begin{array}{l}\text { Range } \\
19-90\end{array}$ & Snoring & Asthma & $\begin{array}{l}1.01[0.76, \\
1.35]\end{array}$ \\
\hline $\begin{array}{l}\text { ten Brinke, } \\
2005 \text { [32] }\end{array}$ & Netherlands & Caucasians & Cross-sectional & $46.30 \%$ & 136 & $27 \%$ & $41.5 \pm 14.1$ & OSA & $\begin{array}{l}\text { Difficult-to-treat } \\
\text { asthma }\end{array}$ & $\begin{array}{l}3.40[1.20 \\
10.4]\end{array}$ \\
\hline Ekici, 2005 [31] & Turkey & Caucasians & Cross-sectional & $97.70 \%$ & 10,224 & $47.50 \%$ & $44.1 \pm 11.6$ & Snoring & Asthma & $\begin{array}{l}1.70[1.50, \\
1.80]\end{array}$ \\
\hline $\begin{array}{l}\text { Gunnbjornsdottir, } \\
2004 \text { [18] }\end{array}$ & Denmark & Caucasians & Cross-sectional & $74.30 \%$ & 16,191 & $47 \%$ & $39.6 \pm 7.1$ & Snoring & Asthma & $\begin{array}{l}1.80[1.34 \\
2.42]\end{array}$ \\
\hline Lu, 2003 [30] & Australia & Caucasians & Cross-sectional & $61 \%$ & 974 & $53 \%$ & Range 2-5 & Snoring & Asthma & $\begin{array}{l}2.00[1.30, \\
3.10]\end{array}$ \\
\hline Vir, 1997 [29] & India & Asians & Case-control & NA & 60 & $43.30 \%$ & $\begin{array}{l}\text { Range } \\
18-28\end{array}$ & Snoring & Asthma & $\begin{array}{l}2.36[0.63, \\
4.92]\end{array}$ \\
\hline
\end{tabular}


Table 4 Meta-analysis of the association between SDB and asthma and its severity risk

\begin{tabular}{llllll}
\hline Subgroups & OR & $\mathbf{9 5 \%} \mathbf{C l}$ & $\boldsymbol{P}$ value & $\boldsymbol{P}_{\boldsymbol{h}}$ & $\boldsymbol{I}^{\mathbf{2}}$ \\
\hline Asthma & 1.55 & $1.44-1.66$ & $<0.001$ & $<0.001$ & $71.70 \%$ \\
Ethnicity & & & & & \\
$\quad$ Caucasian & 1.58 & $1.46-1.70$ & $<0.001$ & $<0.001$ & $75.70 \%$ \\
$\quad$ Asian & 1.40 & $1.12-1.67$ & $<0.001$ & 0.150 & $41.60 \%$ \\
Age group & & & & & \\
$\quad$ Children & 1.58 & $1.35-1.80$ & $<0.001$ & 0.001 & $70.20 \%$ \\
$\quad$ Adults & 1.55 & $1.42-1.67$ & $<0.001$ & $<0.001$ & $77.70 \%$ \\
Study design & & & & & \\
$\quad$ Cross-sectional & 1.56 & $1.45-1.68$ & $<0.001$ & $<0.001$ & $84.4 \%$ \\
$\quad$ Cohort study & 1.46 & $1.16-1.75$ & $<0.001$ & 0.249 & $247 \%$ \\
$\quad$ Case-control & 2.36 & $0.21-4.51$ & 0.310 & n.a. & n.a. \\
Asthma severity & 1.92 & $1.48-2.35$ & $<0.001$ & 0.932 & $0.00 \%$ \\
\hline
\end{tabular}

$\mathrm{OR}$, odds ratio; $\mathrm{Cl}$, confidence interval; $P_{\mathrm{h}}, P$-value of heterogeneity; n.a., not available.

to 16,191 subjects $($ mean $=2584)$. Eight studies investigated whether SDB is an independent risk factor for asthma, while the remaining four studies focused on the correlation between SDB and the severity of asthma.

The result of this meta-analysis was summarized in Table 4. As for SDB and asthma, the random effects model was used since between-study heterogeneity existed $\left(I^{2}=71.7 \%, P<0.001\right)$. The pooled analysis of the eight studies, together with the study presented here, included 59,438 subjects and revealed a significant association between SDB and asthma with OR (95\%CI) of 1.55 (1.441.66) (Figure 2). Subgroup analysis based on ethnicity showed that the magnitude of the effect was similar in both Caucasians and Asians $(\mathrm{OR}=1.58,95 \% \mathrm{CI}$ : 1.461.70, $P<0.001 ;$ OR $=1.40,95 \%$ CI: $1.12-1.67, P<0.001$ ) (Figure 2A). In addition, stratified analyses by age group suggested that SDB was significantly correlated with increased risk of asthma in both children and adults $(\mathrm{OR}=1.58, \quad 95 \% \mathrm{CI}: \quad 1.35-1.80, \quad P<0.001 ; \quad \mathrm{OR}=1.55$, 95\%CI: 1.42-1.67, $P<0.001$ ) (Figure $2 B$ ). Further subgroup analyses based on type of epidemiological study design indicated that the magnitude of the overall effect was similar in cross-sectional and cohort study $(\mathrm{OR}=1.56$, 95\%CI: $1.45-1.68, P<0.001 ; \quad \mathrm{OR}=1.46$, 95\%CI: 1.16 $1.75, P<0.001)$, while the favorable trend disappeared in case-control study (OR $=2.36,95 \% \mathrm{CI}$ : $0.21-4.51, P=0.310)$. As for SDB and asthma severity, since no significant between-study heterogeneity was found $\left(I^{2}=0, P=0.932\right)$, the fixed effects model was applied. The pooled analysis of the four studies involving 1,240 patients revealed that the SDB had an OR for severe asthma of 1.92 (95CI: 1.48 to 2.35) (Table 4).

In this meta-analysis, sensitivity analyses were performed to evaluate the impact of individual study on the overall results. The pooled ORs of SDB with asthma and asthma severity were not affected by the results of any individual study, suggesting the statistically robust results of this meta-analysis. Furthermore, Begg's funnel plot and Egger's linear regression test were performed on the metadata to evaluate publication bias. Egger's test and Funnel plot indicated no publication bias in this metaanalysis $(\mathrm{t}=0.68, P=0.511 ; \mathrm{t}=1.99, P=0.103)$.

\section{Discussion}

Up to now, this is the largest epidemiological study exploring the relationship between SDB and childhood asthma $(n=20,672)$. The reported asthma cases accounted for $3.4 \%$ of our study population, which was higher prevalent than that previously reported in Jinan districts, China (sample aged 0-14 years, 0.7\%) [38]. In addition, this study identified a relatively high prevalence of habitual snoring as well (12.2\%), compared to $10.9 \%$ in Hong Kong children aged 6-12 years [28], 10.0\% in French children aged 5 to 6 years [12], and 11.4\% in British children aged 4 to 7 years [39].

In this context, we have assembled the first national school-based survey in 5-12 years children by parentcompleted questionnaire to assess separately the influence of habitual snoring and OSA on asthma. In the current study, both OSA and habitual snoring were independently associated with onset of asthma after adjusting for traditional asthma risk factors. Although previous studies of stable nocturnal asthma had concluded that impaired quality of sleep, with disturbed sleep during the night, early morning awakenings and daytime sleepiness is common in asthmatic patients, these studies only focused on the effect of asthma on sleep behaviors [40,41]. In recent years, an increased prevalence of sleep-related disorders, such as snoring, self-reported apnea, difficulty in inducing and maintaining sleep, and daytime sleepiness in asthmatic subjects has been reported [18,30,42]. In addition, other studies also have reported patients with SDB are more vulnerable to asthma $[19,20]$. All these studies, together with our cross-sectional study and meta-analysis, support the hypothesis that OSA and habitual snoring are independent risk factors for asthma.

Asthma is a diffuse airway inflammation involving small and large airways and habitual snoring. It is presumably associated with inflammation of upper airways, which could also result in atopy. It is not surprising that they may coexist in the same individual. Although the clear mechanisms underlying these associations remain to be explored, there are several mechanisms how SDB might be linked with asthma. SDB is associated with elevation of pro-inflammatory cytokines, excessive daytime sleepiness (EDS), increased leptin levels, and reduced adiponectin levels [43]. The two adipokines, produced by the adipose tissue that has important pro-inflammatory properties, are 


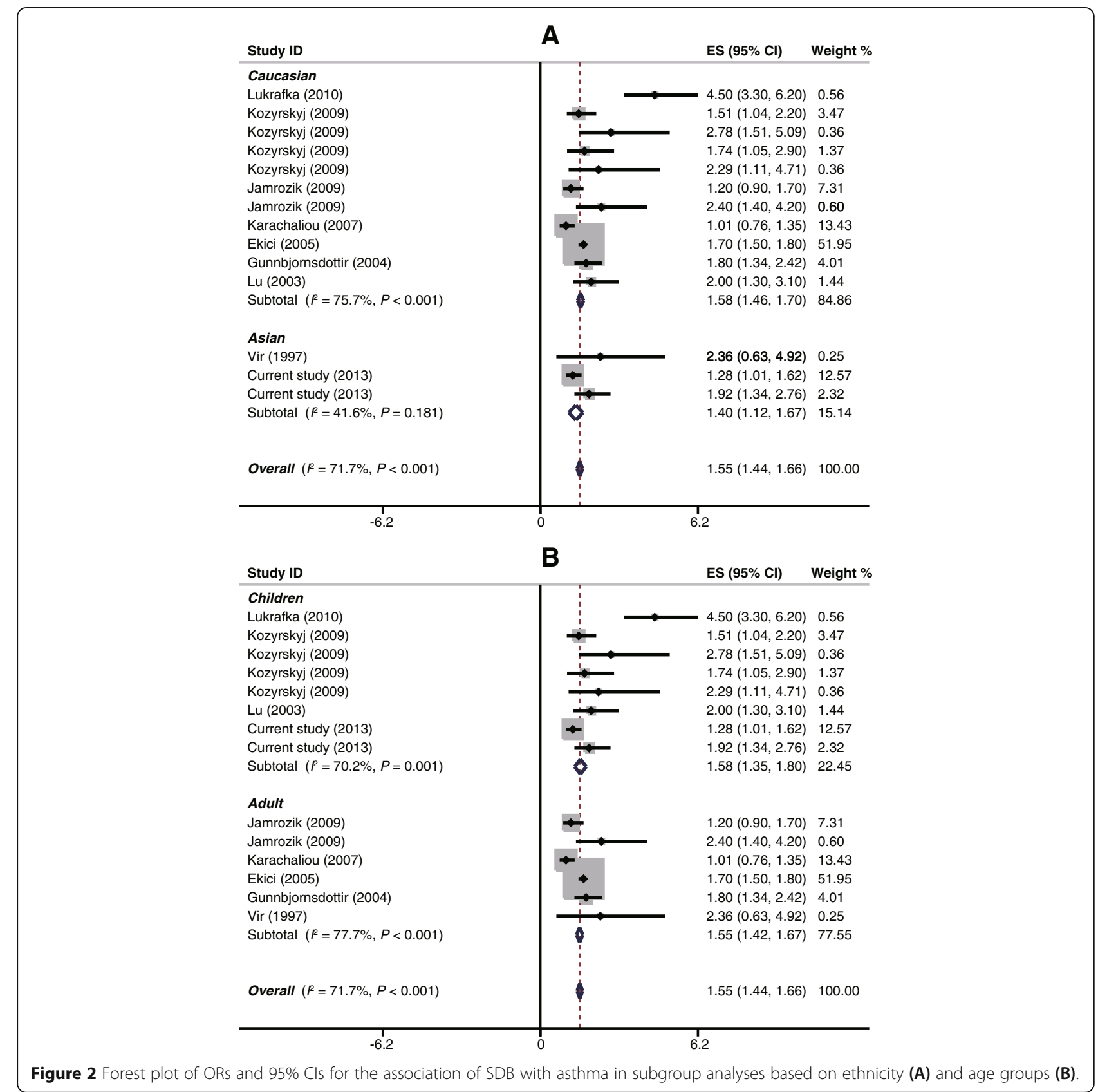

correlated with the occurrence of asthma [44]. Moreover, it is possible that the correlation between asthma and SDB might partially be due to the fact that the presence of upper airway inflammation is common in asthma patients.

As discussed above, SDB was also shown to be associated with the onset of asthma. In this meta-analysis, we further examined the potential interaction between SDB and asthma severity. A clear relationship between reported snoring and severe asthma was identified even when likely confounding factors were adjusted, suggesting that patients who have difficulty achieving adequate asthma control should be screened for SDB. The mechanisms through which SDB worsens asthma still remain largely unclear. Our finding has biological plausibility since Irwin et al. observed that tumor necrosis factor (TNF- $\alpha$ ), one of the proinflammatory cytokines, participate in sleep control and elevate in sleep-deprived adults [45]. TNF- $\alpha$ has been reported as a marker of 'systemic' inflammation in adults with severe asthmatics [46]; neutrophilic airway inflammation has been observed in children with OSA [47]. In addition, there is evidence that the treatment of snoring and OSA with nasal-continuous positive airway pressure (nCPAP) can lead to improved control of asthma both during the night and while awake [48]. 
Several limitations of our study should be addressed. Firstly, this study is questionnaire-based. No objective measurement, such as attended polysomnography, was performed to diagnose SDB. It may cause measurement bias. Meanwhile, it is impossible to determine whether the subjects reporting asthma actually were asthmatics due to the lack of a gold standard. Another drawback was the direction of the cause-effect relationship between SDB and asthma or whether there is a true cause-effect relationship, due to the limitation of cross-sectional data in drawing causality conclusion. The statistical pooling of independent studies also has some disadvantages. Last, the relationship between SDB and asthma severity was not evaluated in our cross-sectional study due to the limited information obtained from the questionnaire. Firstly, meta-analysis cannot correct the limitations of primary research. Secondly, most of included studies for meta-analysis were performed in Caucasians, which restricts the findings to be generalized to other populations in different ethnicities. Finally, although these estimations were based on individual adjusted ORs, and we adjusted our analysis for a broad range of potential confounding factors, there is still a chance of unmeasured or residual confounding. Despite the limitations described above, our study had a large sample size that may increase the validity of results. Further, the meta-analysis summarized the previous studies and our study, which could provide insight into the association between $\mathrm{SDB}$ and asthma stratified by ethnicity and age. Up to now, this is the first national study to investigate whether SDB was an independent risk factor for asthma in school-aged children.

In conclusion, our large epidemiological study, for the first time, examined the association of asthma with habitual snoring and OSA among Chinese children. Our findings provide new evidence to support current asthma guidelines. The pooled data from this large cross-sectional study and meta-analysis will enrich our knowledge on the relationship between SDB (habitual snoring and OSA) and asthma. Further studies should focus on elucidating the underlying mechanism, such as how SDB is associated with asthma.

\section{Abbreviations}

SDB: Sleep-disordered breathing; OSA: Abstructive sleep apnea; OR: Odd ratio.

\section{Competing interests}

The authors declare that they have no competing interests.

\section{Authors' contributions \\ Conception and design: SX and LS; analysis and interpretation: LL, XZ, LS, SX, $J X, Y C$, and FJ; drafting of the manuscript for important intellectual content: $L L$; revising the manuscript for important intellectual content: $L S, X Z$, TS; administrative, techanical, and material support: LS, SX, JX, YC, and FJ; and final approval of the manuscript: SX, LS, LL, XZ, LS, SX, JX, YC, FJ, and TS.}

\section{Disclosure statement}

This study was funded by Grants from MOE - Shanghai Key Laboratory of Children's Environmental Health (06DZ22024), the Key Discipline in Public Health of Shanghai Municipal Education Commission, National Natural Science Foundation of China (81072314), Innovation Program of Shanghai Municipal Education Commission (13YZ034), 2012 Shanghai public health academic leader project (GWDTR201222), and Shanghai Jiao Tong University medicine and engineering cross fund project (YG2013MS13).

\section{Author details}

${ }^{1}$ Xin Hua Hospital, School of Medicine, Shanghai Jiaotong University, Shanghai, China. ${ }^{2}$ School of Public Health, Shanghai Jiao Tong University School of Medicine, 227 South Chongqing Road, Shanghai 200127, PR China. ${ }^{3}$ School of Public Health and Social Work, Queensland University of Technology, Brisbane, Qld, Australia. ${ }^{4}$ Children's Medical Center, School of Medicine, Shanghai Jiaotong University, Shanghai, China. ${ }^{5} \mathrm{MOE}$ - Shanghai Key Laboratory of Children's Environmental Health, Xinhua Hospital, Shanghai Jiao Tong University School of Medicine, 1665 Kong Jiang Road, Shanghai 200092, China.

Received: 5 December 2014 Accepted: 24 April 2015

Published online: 10 May 2015

\section{References}

1. Kudzyte J, Griska E, Bojarskas J. Time trends in the prevalence of asthma and allergy among 6-7-year-old children. Results from ISAAC phase I and III studies in Kaunas, Lithuania. Medicina (Kaunas). 2008;44:944-52.

2. Becker AB. Challenges to treatment goals and outcomes in pediatric asthma. J Allergy Clin Immunol. 2002;109:S533-538.

3. Simmons JC. Improving care and quality of life for all asthma patients. Qual Lett Healthc Lead. 2001;13:2-13.

4. Becker $A B$, Chan-Yeung M. Primary prevention of asthma. Curr Opin Pulm Med. 2002;8:16-24.

5. Beuther DA, Weiss ST, Sutherland ER. Obesity and asthma. Am J Respir Crit Care Med. 2006;174:112-9.

6. Ross KR, Hart MA, Storfer-Isser A, Kibler AM, Johnson NL, Rosen CL, et al. Obesity and obesity related co-morbidities in a referral population of children with asthma. Pediatr Pulmonol. 2009;44:877-84.

7. Kheirandish-Gozal L, Dayyat EA, Eid NS, Morton RL, Gozal D. Obstructive sleep apnea in poorly controlled asthmatic children: effect of adenotonsillectomy. Pediatr Pulmonol. 2011;46:913-8.

8. Kaiser P. Obstructive sleep apnea in poorly controlled asthmatic children: effect of adenotonsillectomy. Pediatr Pulmonol. 2012:47:311. discussion 312-314.

9. Schechter MS. Technical report: diagnosis and management of childhood obstructive sleep apnea syndrome. Pediatrics. 2002;109, e69.

10. Institute NHLaB. Expert Panel Report 3 (EPR-3): Guidelines for the Diagnosis and Management of Asthma-Summary Report 2007. J Allergy Clin Immunol. 2007;120:S94-138.

11. Baldwin CM, Quan SF. Sleep disordered breathing. Nurs Clin North Am. 2002;37:633-54

12. Teculescu DB, Caillier I, Perrin P, Rebstock E, Rauch A. Snoring in French preschool children. Pediatr Pulmonol. 1992;13:239-44.

13. Sulit LG, Storfer-Isser A, Rosen CL, Kirchner HL, Redline S. Associations of obesity, sleep-disordered breathing, and wheezing in children. Am J Respir Crit Care Med. 2005;171:659-64.

14. Ramagopal M, Scharf SM, Roberts DW, Blaisdell CJ. Obstructive sleep apnea and history of asthma in snoring children. Sleep Breath. 2008;12:381-92.

15. Li S, Jin X, Yan C, Wu S, Jiang F, Shen X. Habitual snoring in school-aged children: environmental and biological predictors. Respir Res. 2010;11:144.

16. Fadzil Abdullah AA, Jamalludin AR, Norrashidah AW, Norzila MZ, Asiah Kassim K, Rus Anida A, et al. Prevalence of sleep disordered breathing symptoms among Malay school children in a primary school in Malaysia. Med J Malaysia. 2012;67:181-5.

17. Gutierrez MJ, Zhu J, Rodriguez-Martinez CE, Nino CL, Nino G. Nocturnal phenotypical features of obstructive sleep apnea (OSA) in asthmatic children. Pediatr Pulmonol. 2013;48:592-600.

18. Gunnbjornsdottir Ml, Omenaas E, Gislason T, Norrman E, Olin AC, Jogi R, et al. Obesity and nocturnal gastro-oesophageal reflux are related to onset of asthma and respiratory symptoms. Eur Respir J. 2004;24:116-21.

19. Kozyrskyj AL, Kendall GE, Zubrick SR, Newnham JP, Sly PD. Frequent nocturnal awakening in early life is associated with nonatopic asthma in children. Eur Respir J. 2009;34:1288-95.

20. Lukrafka JL, Fuchs SC, Moreira LB, Picon RV, Fischer GB, Fuchs FD. Performance of the ISAAC questionnaire to establish the prevalence of asthma in adolescents: a population-based study. J Asthma. 2010;47:166-9.

21. Stein MA, Mendelsohn J, Obermeyer WH, Amromin J, Benca R. Sleep and behavior problems in school-aged children. Pediatrics. 2001;107, E60. 
22. Smaldone A, Honig JC, Byrne MW. Sleepless in America: inadequate sleep and relationships to health and well-being of our nation's children. Pediatrics. 2007;119 Suppl 1:S29-37.

23. Li SH, Jin XM, Shen XM, Wu SH, Jiang F, Yan CH, et al. [Development and psychometric properties of the Chinese version of Children's Sleep Habits Questionnaire]. Zhonghua Er Ke Za Zhi. 2007:45:176-80.

24. Li S, Zhu S, Jin X, Yan C, Wu S, Jiang F, et al. Risk factors associated with short sleep duration among Chinese school-aged children. Sleep Med. 2010;11:907-16.

25. Owens JA, Spirito A, McGuinn M. The Children's Sleep Habits Questionnaire (CSHQ): psychometric properties of a survey instrument for school-aged children. Sleep. 2000;23:1043-51.

26. Jackson D, White IR, Riley RD. Quantifying the impact of between-study heterogeneity in multivariate meta-analyses. Stat Med. 2012:31:3805-20.

27. Peters JL, Sutton AJ, Jones DR, Abrams KR, Rushton L. Comparison of two methods to detect publication bias in meta-analysis. JAMA. 2006;295:676-80.

28. Zintzaras $E$, loannidis JP. Heterogeneity testing in meta-analysis of genome searches. Genet Epidemiol. 2005;28:123-37.

29. Vir R, Bhagat $R$, Shah A. Sleep disturbances in clinically stable young asthmatic adults. Ann Allergy Asthma Immunol. 1997;79:251-5.

30. Lu LR, Peat JK, Sullivan CE. Snoring in preschool children: prevalence and association with nocturnal cough and asthma. Chest. 2003;124:587-93.

31. Ekici A, Ekici M, Kurtipek E, Keles H, Kara T, Tunckol M, et al. Association of asthma-related symptoms with snoring and apnea and effect on healthrelated quality of life. Chest. 2005;128:3358-63.

32. ten Brinke A, Sterk PJ, Masclee AA, Spinhoven P, Schmidt JT, Zwinderman $\mathrm{AH}$, et al. Risk factors of frequent exacerbations in difficult-to-treat asthma. Eur Respir J. 2005;26:812-8.

33. Karachaliou F, Kostikas K, Pastaka C, Bagiatis V, Gourgoulianis Kl. Prevalence of sleep-related symptoms in a primary care population - their relation to asthma and COPD. Prim Care Respir J. 2007:16:222-8.

34. Jamrozik E, Knuiman MW, James A, Divitini M, Musk AW. Risk factors for adult-onset asthma: a 14-year longitudinal study. Respirology. 2009;14:81421.

35. Teodorescu M, Consens FB, Bria WF, Coffey MJ, McMorris MS, Weatherwax $\mathrm{KJ}$, et al. Predictors of habitual snoring and obstructive sleep apnea risk in patients with asthma. Chest. 2009:135:1125-32

36. Ross KR, Storfer-Isser A, Hart MA, Kibler AM, Rueschman M, Rosen CL, et al. Sleep-disordered breathing is associated with asthma severity in children. J Pediatr. 2012;160:736-42.

37. Teodorescu M, Polomis DA, Teodorescu MC, Gangnon RE, Peterson AG, Consens FB, et al. Association of obstructive sleep apnea risk or diagnosis with daytime asthma in adults. J Asthma. 2012;49:620-8.

38. Wang D, Xiao W, Ma D, Zhang Y, Wang Q, Wang C, et al. Cross-sectional epidemiological survey of asthma in Jinan, China. Respirology. 2013;18:313-22.

39. Ali NJ, Pitson D, Stradling JR. Natural history of snoring and related behaviour problems between the ages of 4 and 7 years. Arch Dis Child. 1994;71:74-6.

40. Janson C, Gislason T, Boman G, Hetta J, Roos BE. Sleep disturbances in patients with asthma. Respir Med. 1990;84:37-42.

41. Fitzpatrick MF, Engleman H, Whyte KF, Deary IJ, Shapiro CM, Douglas NJ. Morbidity in nocturnal asthma: sleep quality and daytime cognitive performance. Thorax. 1991;46:569-73.

42. Janson C, De Backer W, Gislason T, Plaschke P, Bjornsson E, Hetta J, et al. Increased prevalence of sleep disturbances and daytime sleepiness in subjects with bronchial asthma: a population study of young adults in three European countries. Eur Respir J. 1996;9:2132-8.

43. Tsaoussoglou M, Bixler EO, Calhoun S, Chrousos GP, Sauder K, Vgontzas AN. Sleep-disordered breathing in obese children is associated with prevalent excessive daytime sleepiness, inflammation, and metabolic abnormalities. J Clin Endocrinol Metab. 2010;95:143-50.

44. Nagel G, Koenig W, Rapp K, Wabitsch M, Zoellner I, Weiland SK. Associations of adipokines with asthma, rhinoconjunctivitis, and eczema in German schoolchildren. Pediatr Allergy Immunol. 2009;20:81-8.

45. Irwin MR, Wang M, Campomayor CO, Collado-Hidalgo A, Cole S. Sleep deprivation and activation of morning levels of cellular and genomic markers of inflammation. Arch Intern Med. 2006;166:1756-62.

46. Silvestri M, Bontempelli M, Giacomelli M, Malerba M, Rossi GA, Di Stefano A, et al. High serum levels of tumour necrosis factor-alpha and interleukin-8 in severe asthma: markers of systemic inflammation? Clin Exp Allergy. 2006;36:1373-81.

47. Li AM, Hung E, Tsang T, Yin J, So HK, Wong E, et al. Induced sputum inflammatory measures correlate with disease severity in children with obstructive sleep apnoea. Thorax. 2007;62:75-9.

48. Chan CS, Woolcock AJ, Sullivan CE. Nocturnal asthma: role of snoring and obstructive sleep apnea. Am Rev Respir Dis. 1988;137:1502-4.

\section{Submit your next manuscript to BioMed Central and take full advantage of:}

- Convenient online submission

- Thorough peer review

- No space constraints or color figure charges

- Immediate publication on acceptance

- Inclusion in PubMed, CAS, Scopus and Google Scholar

- Research which is freely available for redistribution 